COMEAU, Robert et Michel LÉVESQUE, Le Parti québécois :

bibliographie rétrospective. Québec, Bibliothèque de

l'Assemblée nationale, coll. " Bibliographie et documentation ",

$\mathrm{n}^{0} 38,1991.132 \mathrm{p}$.

LÉVESQUE, Michel et Robert COMEAU, Le Parti libéral du

Québec : bibliographie rétrospective (1867-1990). Québec, Bibliothèque de l'Assemblée nationale, coll. " Bibliographie et documentation ", $\mathrm{n}^{0}$ 39, 1991. xii-198 p.

\title{
René Castonguay
}

Volume 45, numéro 4, printemps 1992

URI : https://id.erudit.org/iderudit/305034ar

DOI : https://doi.org/10.7202/305034ar

Aller au sommaire du numéro

\section{Éditeur(s)}

Institut d'histoire de l'Amérique française

ISSN

0035-2357 (imprimé)

1492-1383 (numérique)

Découvrir la revue

Citer ce compte rendu

Castonguay, R. (1992). Compte rendu de [COMEAU, Robert et Michel LÉVESQUE, Le Parti québécois : bibliographie rétrospective. Québec, Bibliothèque de l'Assemblée nationale, coll. « Bibliographie et documentation », $\mathrm{n}^{0}$ 38, 1991. 132 p. / LÉVESQUE, Michel et Robert COMEAU, Le Parti libéral du Québec : bibliographie rétrospective (1867-1990). Québec, Bibliothèque de l'Assemblée nationale, coll. « Bibliographie et documentation ", $\mathrm{n}^{0}$ 39, 1991. xii-198 p.] Revue d'histoire de l'Amérique française, 45(4), 630-631.

https://doi.org/10.7202/305034ar services d'Érudit (y compris la reproduction) est assujettie à sa politique d'utilisation que vous pouvez consulter en ligne. 
COMEAU, Robert et Michel LÉVESQUE, Le Parti québécois: bibliographie rétrospective. Québec, Bibliothèque de l'Assemblée nationale, coll. «Bibliographie et documentation», n 38, 1991. $132 \mathrm{p}$.

LÉVESQUE, Michel et Robert COMEAU, Le Parti libéral du Québec: bibliographie rétrospective (1867-1990). Québec, Bibliothèque de l'Assemblée nationale, coll. «Bibliographie et documentation», $\mathrm{n}^{\circ} 39$, 1991. xii-198 p.

Comeau et Lévesque nous présentent ici deux ouvrages de référence qui seront très appréciés puisqu'ils remplissent un grand vide dans l'historiographie québécoise. D'une présentation sobre mais efficace, ces répertoires se consultent aisément et résisteront bien à une utilisation fréquente. Dans les deux cas, l'introduction éclaire le cheminement méthodologique suivi par les auteurs. C'est ainsi que nous avons droit à une présentation du Parti libéral et de son histoire. Cette approche permet de retrouver dans la bibliographie du PLQ des ouvrages traitant des Rouges d'avant 1867. Une telle démarche aurait été souhaitable également pour le Parti québécois. L'utilisateur aurait ainsi pu cerner davantage le cheminement politique qui a mené à la naissance de ce parti, et mieux identifier les mouvements qui se sont finalement groupés sous sa bannière.

Les divisions utilisées à l'intérieur des bibliographies ne sont pas les mêmes dans les deux ouvrages. Alors qu'un plan chronologique est utilisé pour le PLQ, un plan par catégories est préféré pour le PQ (publications générales, publications du parti et publications gouvernementales). La division chronologique nous semble préférable puisqu'elle tend à regrouper par périodes les titres traitant du même sujet.

Dans chacune des bibliographies se côtoient articles de journaux, ouvrages généraux ou spécialisés, articles de revues, publications officielles, et, 
pour ce qui concerne plus particulièrement les libéraux du début du siècle, pamphlets politiques et discours imprimés. Malheureusement des manques existent dans ces deux dernières catégories; mais personne ne demande la perfection quand il s'agit de telles reliques. À vrai dire, le premier point faible des bibliographies se trouve plutôt dans la volonté des auteurs de mentionner autant de fois que nécessaire un ouvrage dont le contenu recouperait plus d'une division. Il semble ici y avoir eu des ratés. Ne prenons qu'un exemple, dans la bibliographie du PLQ. La biographie de Taschereau la plus complète, celle de Bernard Vigod, aurait dû se retrouver à la fois dans la section le concernant et dans la section touchant le gouvernement de Lomer Gouin, puisque Taschereau a été un important ministre de Gouin. Or, elle n'est mentionnée que dans la section réservée à Taschereau et à ses successeurs. Selon l'intention des auteurs, cet ouvrage aurait dû apparaître dans les deux sections.

Chacune des bibliographies contient des outils pour aider le chercheur. Les deux possèdent un index des noms des auteurs ainsi que des personnes mentionnées dans les titres des œuvres. Un autre point faible de ces bibliographies, le principal selon nous, c'est qu'ils n'offrent pas d'indexmatières, instrument pourtant plus qu'indispensable dans ce genre d'ouvrages. C'est ainsi qu'il nous est impossible, par exemple, de chercher des informations sur les relations entre le Parti québécois et les milieux financiers autrement qu'en consultant chacun des titres. Ces bibliographies perdent donc beaucoup de leur raison d'être et se transforment presque en simples listes énumératives. Notons la présence dans la bibliographie du PQ d'une chronologie reprenant les principales étapes de cette formation politique. Plus complètes, les annexes du PLQ nous donnent entre autres la liste de ses chefs, les résultats électoraux et des informations sur les congrès du parti.

Produite avant la bibliogaphie du PLQ, celle du PQ semble donc moins complète, moins achevée que ne l'est sa sœur cadette. Mais malgré leurs faiblesses, ces bibliographies doivent trouver une place dans les bibliothèques des chercheurs. Elles nous font constater l'intérêt suscité par un parti comme le $P Q$, mais également prendre conscience du manque criant d'études sur la politique québécoise d'avant Taschereau. 